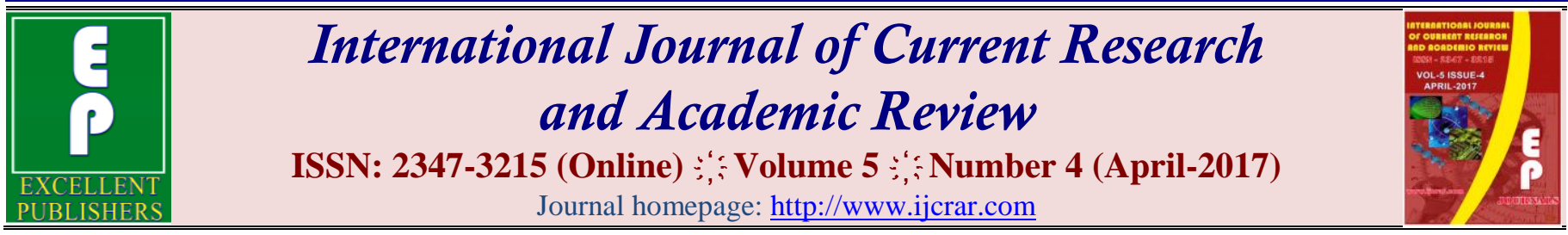

doi: https://doi.org/10.20546/ijcrar.2017.504.002

\title{
FM Radio and Listening Habits of Younger Generation: A Study of Four Major Markets of Delhi, India
}

\author{
Romica Bhat* and Neemo Dhar \\ ${ }^{1}$ Research Scholar, ${ }^{2}$ Research Guide, Manav Rachna International University, Faridabad, India \\ *Corresponding author
}

\begin{abstract}
Mass communication is regarded as the forth pillar of the society. It can mould society in whatever way it wants. Ever since it's being, it has always given something positive to the society. Tools and techniques of mass communication have evolved over the years and it's worthwhile to say that whatever form it acquired, it has disposed off its duties diligently. Radio being the first in the line of Broadcast medium has always been looked upon for information, entertainment etc and it in response has delivered what was expected of it. Radio evolved and took the shape of FM radio over a period of time and subsequently, FM radio tried to contribute to the society. FM radio has always been a hit among youngsters. In this paper factors behind its popularity will be studied and analyzed. We will also find out the areas where it can excel and extend its reach.
\end{abstract}

\section{Article Info}

Accepted: 28 March 2017

Available Online: 20 April 2017

\section{Keywords}

Broadcast medium, Youngsters, Factors behind popularity, Areas to excel.

\section{Introduction}

Since inception, radio has been catering to the communication needs of various genres of the Indian society. During its life span it has to undergo various challenges in relation to playing a meaningful role in bringing out the desirable changes in the society. In order to make understand the message, radio has gone through tremendous changes in programming and reach across the length and breadth of the country. In the success journey of radio the contribution of FM has been notable. Its crispness and packaging made radio an unforgotten experience. FM since its birth has relentlessly worked hand in hand with radio making it more accessible and entertaining for the listeners. FM has regularly innovated and evolved through time and it searches for new and appropriate formats as well as suitable communication contents for meeting the objectives (Santoki, 2015). The gainful impact of radio and its formats has been recognized by people and development agencies over the period of time. Since last few decades FM has witnessed the Indian journey of development and as an institution of communication given to catalyze the process of change on the one hand as well as preserver of a vibrant cultural heritage on the other.

The relevance of radio in the process of social development and change has been robust primarily because of its innate strength to be in tune with time (Kujur and Jha, 2009). FM as a mass medium has its own course of evolution and comes to be accepted as a means to support the efforts of development in modernizing society. In keeping with the respective social objectives, the concern of radio was to aid the process of changing lives of those who exist on the margins of development on one hand and maintaining its relevance as a dynamic society and on the threshold of taking a quantum leap forward on the other (Kujur and Jha, 2009). In the 
course of its decorated years, radio caters to the need of everyone. Radio FM has formulated its programming for each and everyone. It is believed that one of the biggest harbingers of changes in any society is its youngsters. FM has tapped this genre quiet efficiently. From the past few years FM has designed itself according to the choice and needs of the younger generation of the country. In response young society has also accepted FM with both hands. We can see a tremendous rise in popularity of FM over the years. FM can be regarded as the most popular means of spreading information, irrespective of the boundaries. FM is very appealing because of some of its prominent features like interactivity and its capability to provoke dialogue and to solicit the participation of all strata's of population with lower production cost and extreme versatility (Ezekiel and Peter, 2014). According to TAM India FM penetration in 2011 has been highest in Delhi with a growth of $88 \%$ as compared to 2007 and there is no looking back. Expected revenue growth of private FM radio in 2017 is 27.4\% (Akoijam, 2012).

\section{Objective of the Study}

1. To study the FM listening habits of youngsters in Delhi/NCR.

2. To study their frequency of FM radio listening.

3 . To study the preferred programme.

4. To study its impact on information dissemination/ entertainment.

\section{Literature Review}

(Ajaegbu, 2015) considers radio as a source of entertainment and information driven from it can be used for decision making, logical arguments and more. He further states radio as a credible source of knowledge broadcaster and advices them to continue to perform as an indispensible part of media. (Onabajo, 1999) views radio as a powerful medium of transporting message across boundaries of space and time. He states radio as a wonderful and only medium that can connect with people irrespective of their qualification and background. Further he asserts it as a powerful instrument in the area of public enlightenment, health issues, family planning, cultural reawakening and other social developments. (Kuewemi, 2009) admires radio as a great companion. He describes it as a medium which can talk to millions, yet talking to them individually. He feels the power of radio when it is discussing something relevant, powerful and sensible to them. (Tachhi, 2011) feels that the presence of radio is everyone's life but we are yet to realize it. She feels radio ubiquitous, but quietly as it is invisible. In order to talk more on Radio she organized a conference on Radio "Radiocracy" at Cardiff to demonstrate the resurgence of interest in academics studies of radio but also the innovative ways in which radio can be used. Tacchi advocates use of radio in the field of development especially in the developing countries like India. She further states that in the age of digitization it is necessary to evolve radio at various platforms. Rajalakshmi (2012) researcher tries to analyze the marketing strategies adopted by FM radio over the years. The findings show FM radio as the cheapest medium for advertising, the most listeners of FM radio are students and working men, 60-70\% people listening radio while driving their car, the average daily listeners in households are $54 \%$ as compared to $85 \%$. Ananthi (2007) researcher studied the preference of respondents regarding FM radio in Chennai. The findings show that there is a proportionate relation between the occupation of the listeners and the number of days he/she listens to FM radio. There is no significant difference between different age group with respect to the time when the respondents listen to FM Radio, information sharing on FM radio \& programs on FM radio are the most important attributes affecting consumers' behavior, consumers don't like to listen advertisement on radio and Radio Mirchi is the most preferred FM radio.

\section{Research Methodology}

This research is based on quantitative approach. A survey was conducted to find out the attitude of youngsters towards FM radio. For the purpose the area of study chosen was four major markets of Delhi (Lajpat Nagar, Laxmi Nagar, Sarojini Nagar and Karol Bagh). These markets were chosen on the basis of maximum availability of youngsters in them. The sample size taken for the same was 200 (50 from each). The findings were summed up in pie charts and bar graphs.

\section{Data collection and Findings (based on questions)}

\section{Do You Listen Radio?}

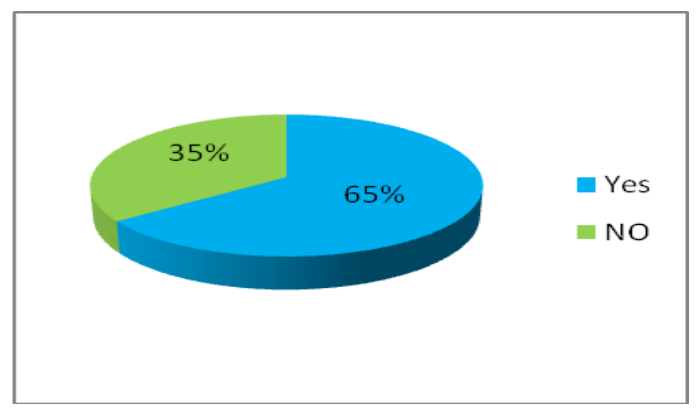


As per the survey among 200 respondents $65 \%$ listen to radio whereeas $35 \%$ are indifferent to it due to various reasons of non availablity of time, interest or inclination towards other medium of communication.

\section{Why don't you listen to radio?}

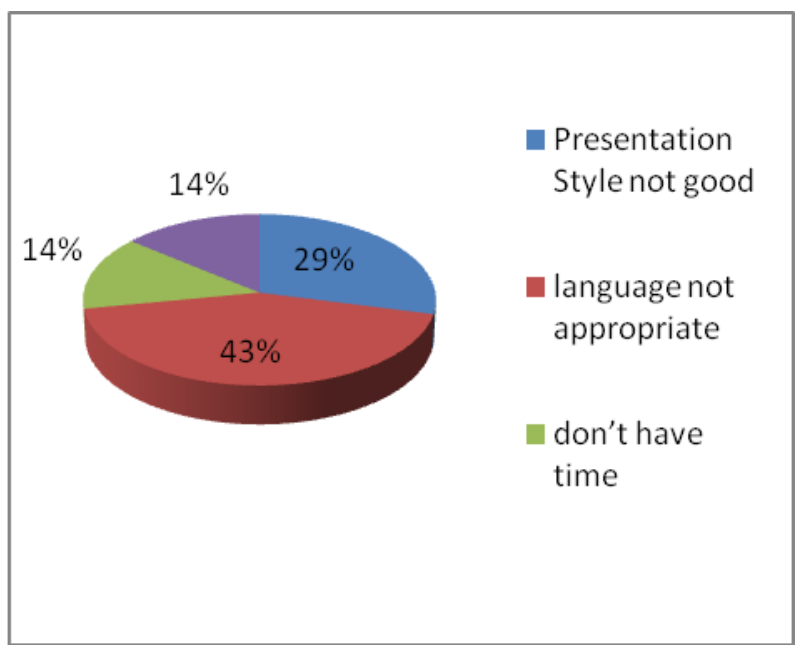

FM radio may be a part of life for many but there is also a section of society who are not very fond of this medium. A majority of this lot find the language of FM radio not upto the mark, presentation style not good. The main reason behind it is the language. Radio industry need to work on it.

\section{How many times you listen radio in a day?}

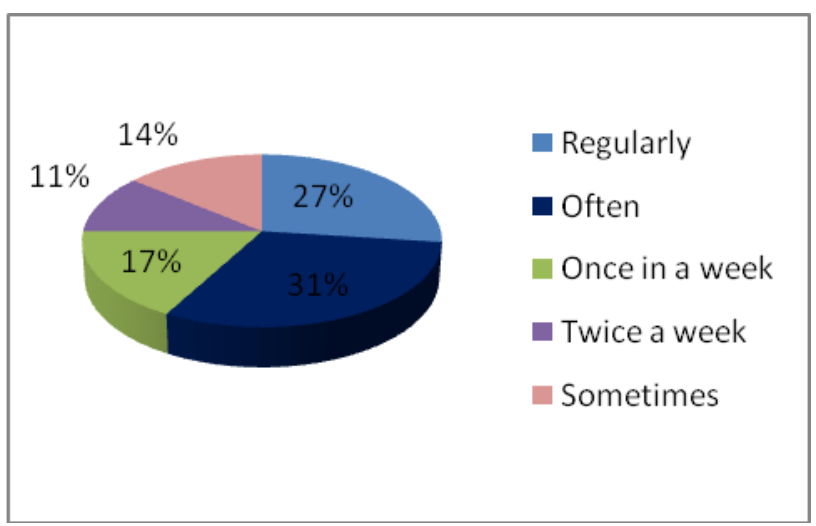

$27 \%$ of the sample are radio regulars while a majority of $31 \%$ are not regular listeners. $17 \%$ of youngsters are listeneing to radio once in a week $14 \%$ are sometime listeners. Looking at the above data one can easily understand that radio is there though not a regular habit but it is a part of life.

\section{At what time you listen radio?}

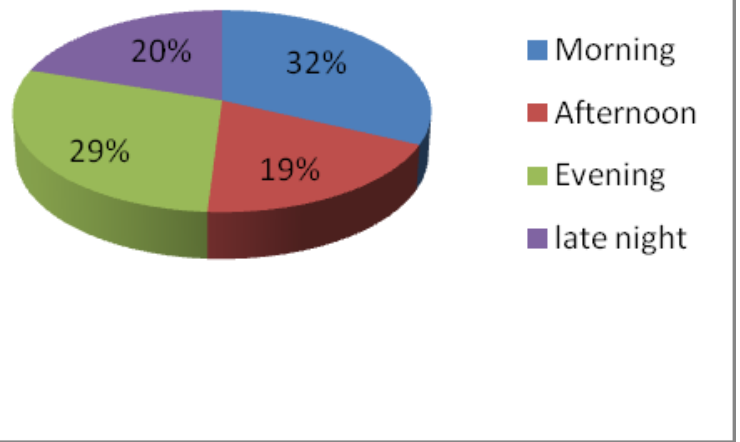

It is reflected in the survey that maximum respondents prefer morning and evening time to listen radio. As this the time when they are in transit and prefer listening to FM on their mobile or car stereo. This time is the most prefered time amongst youth. Late night time is prefered by those who need to sooth themselves by listening to light music.

Which Radio station you like the most?

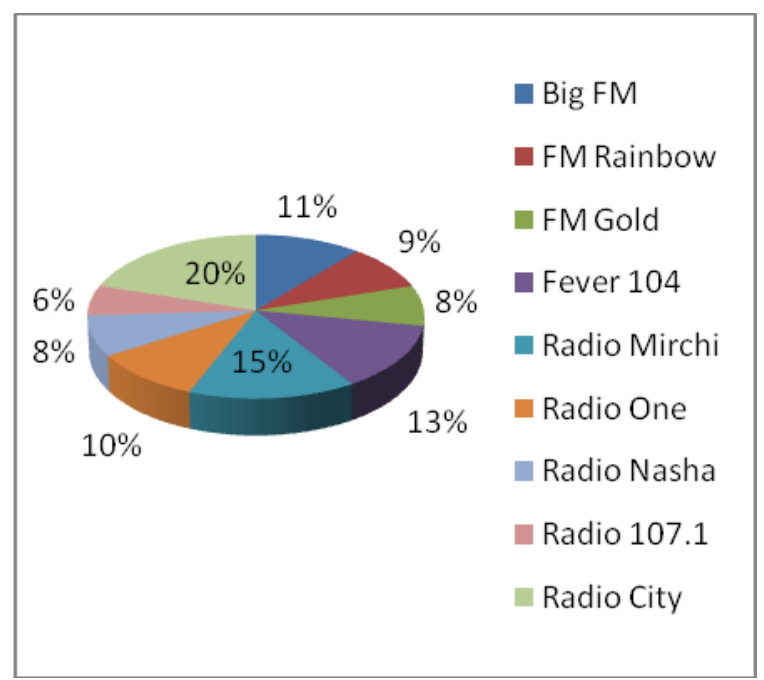

Out of 9 main FM stations available in the capital of India , Radio City is favourite aming the youth. Radio Nasha, FM channel just launched is also pacing up in the race and trying to tap into the hearts of youngsters. FM Rainbow and Gold is favourite among old melody listeners. 


\section{What attracts you to listen a radio programme?}

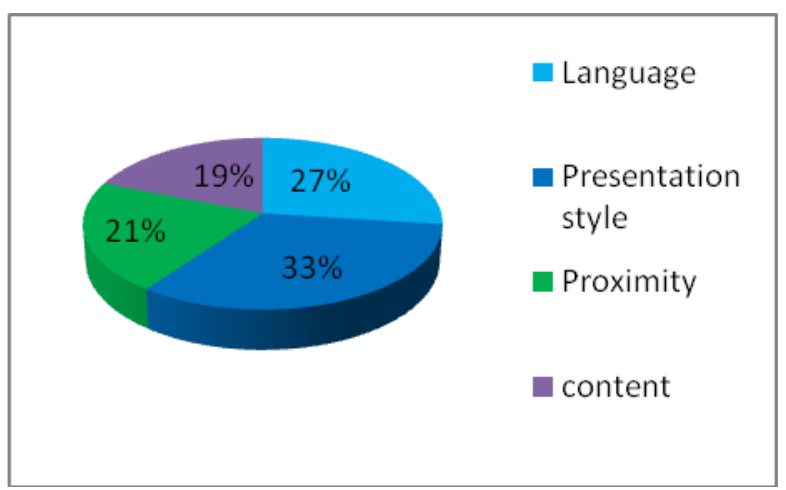

Its presesntation style of FM radio that is the winner. Youngsters find presentation style of FM radio stations fascinating and according to their style. $33 \%$ of population like radio because of its preseantation style while $27 \%$ are inclined towards the language.

Radio RJ's als provide a sense of proximiy to its listeners. Being an audio visual medium they deliver everything acting as eyes and eyers of the listeners and this proximity has been realised by $21 \%$ of the universe size. $19 \%$ of the sample find the content of FM radio attractive.

\section{Does FM radio help you in updating yourself?}

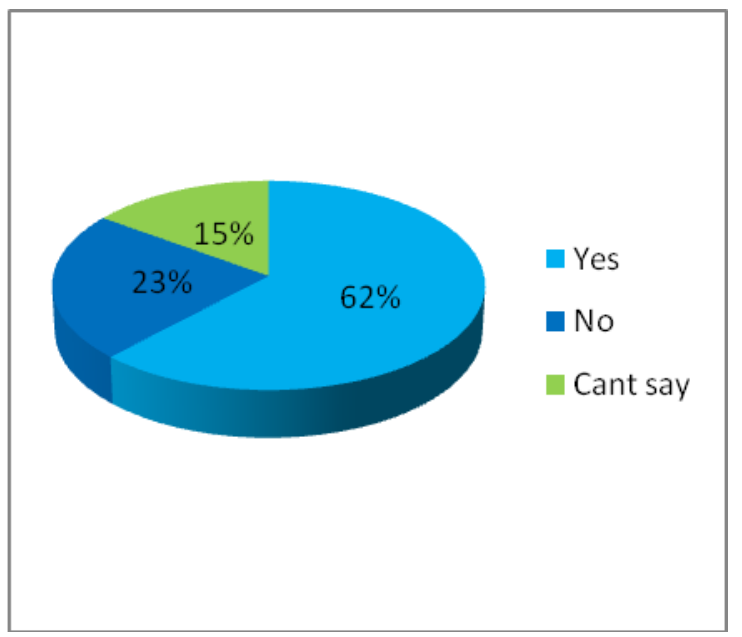

Broadcast of news is not allowed on FM radio stations on their own except Government FM channels still FM radio presenters try to update its listeners through gags, content and interviews. $62 \%$ respondents identify with the efforts while $15 \%$ don't have any say on it.
Do you think pranks done by RJ's on listeners are good?

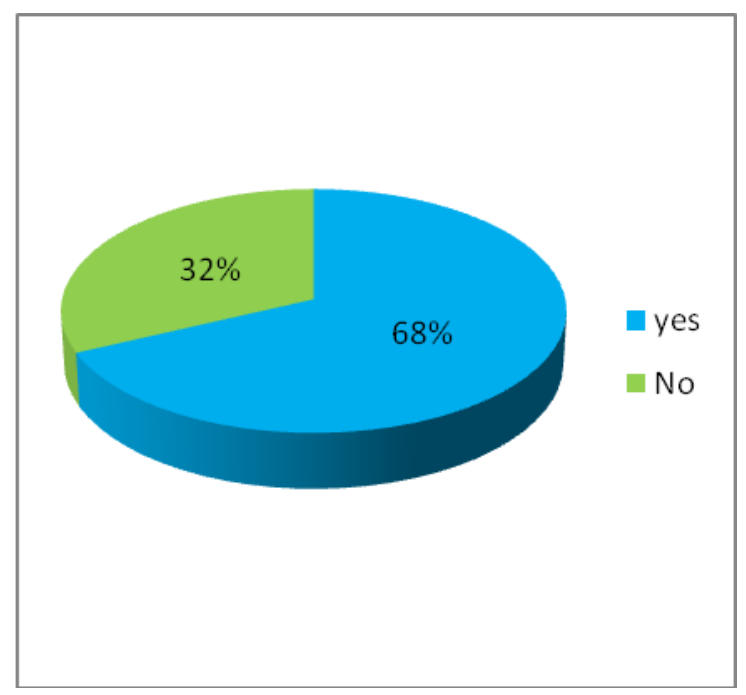

In order to keep the crisp and laughing quotient always high RJ perform verious pranks on their listeners which are quiet a hit among them. 68\% percent find these pranks amusing and want them to be a part of programming. While $32 \%$ are not happy with the pranks played by these presenters on the audience. They feel that it's the invasion of their privacy and it also preent them in a very bad light in front of listeners.

Do you think language used by radio jockeys is appropriate

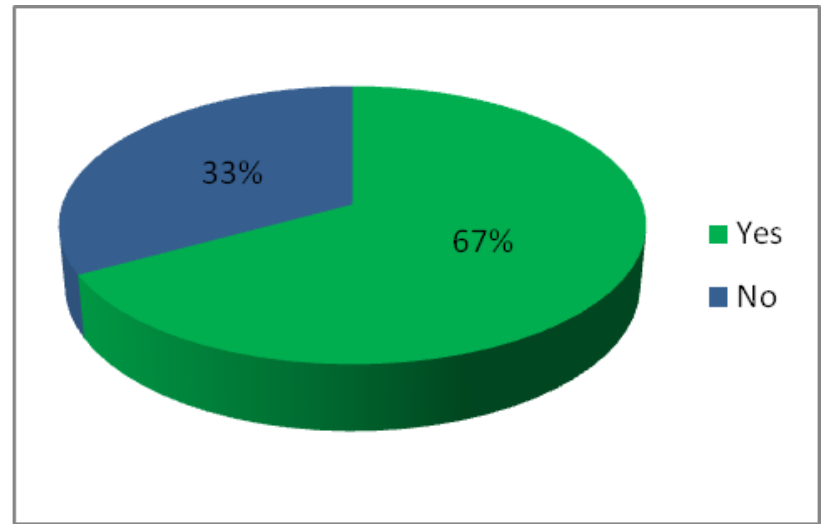

Though maximum listeners (67\%) find language of RJ's appropriate, there is a section of society which wants a rectification. 33\% respondents are not happy with the language used in the programmes. Statements like "Aap ke zamane ka Baap ke Zamane ka nahi”, "Lag gayi Boss" etc don't go down well with the listeners. Its not onle sataments sometimes RJ's indulge in exchange on 
Non veg jokes also which should also be refrained as any medium of communication is regarded as the reflection of society and imbibed by the youngsters at a very faster pace.

\section{Which programme format you like the most?}

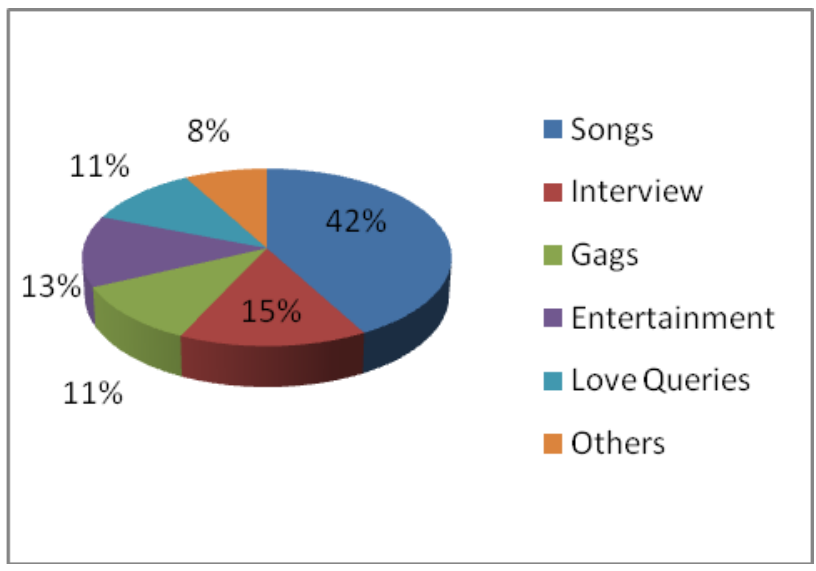

For youngsters radio menas songs $42 \%$ of youngsters listen to radio because of its song next big winner in programme category are interviews of celebrities and people of social importance. Through these programmes listerners get a chance to know them better, peep into their life and know their opinion on different issues. 13\% of sample can relate itself with programmes which are high on entertainment quotient varing from gossips to pranks to disscussion on any relevant topic in a very satarical way. Gags and love query related programmes are on equal percentage of $11 \%$. While rest of the programme formates comprise the $8 \%$ liking of the sample.

\section{Do you think FM creates social awareness?}

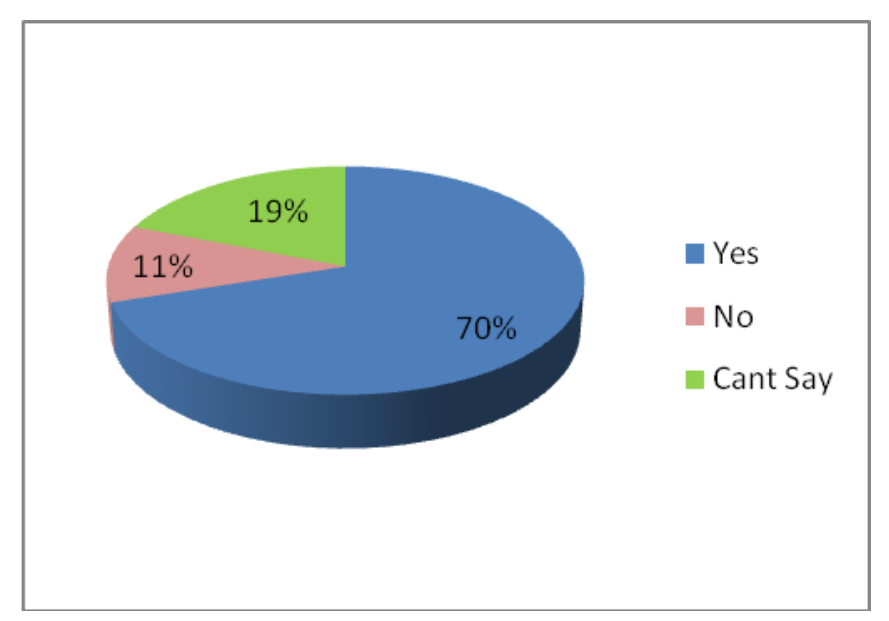

$70 \%$ of listeners agree that FM radio stations try to create social awareness in public. Regular social messages and plays are a hit among them; it updates them about various issues related to health, sanitation, education and environment. $11 \%$ of the samples disagree with the statement, they feel that the deliverance of message on FM radio is so light that it often fails to make an impact while $19 \%$ sample size was indifferent to the idea they have were having no say on the question.

\section{Conclusion}

At the time when radio was on decline, FM radio came to its rescue. Today we can feel its presence everywhere. FM is mainly endorsed by youngsters. The study establishes the fact that the radio listening habits among the sample size is positive and they have adequate access to radio within the environment. Despite regular changes in technology FM still finds a place in the hearts of the public. It has emerged as a reliable source of information. A good population is still inclined towards FM. It's the programming style of the FM that makes it a hit. The data shows that there is still more to do in case of content and language. There is still a segment of society which is not happy with the way FM has shaped up. FM industry needs to tap into this sphere. They need to customize their show keeping in view the demands from every walk of life. More programmes.

\section{References}

Akiojam Indira. 2012. Radio, http://www.thehoot.org/statistics/radio-5844.

Ananthi N. 2007. Emerging Paradigms in MarketingA Study on the FM Radio Market in Chennai City, http://www.presidencybusinessschool.org.

Ezekiel, B. and O. Peter. 2014. An Assessment of the Use of Radio and other Means of Information Dissemination by the Residents of AdoEkiti, Ekiti-State, Nigeria, http://digitalcommons.unl.edu/ cgi $/$ viewcontent.cgi article $=2747 \&$ context $=$ li bphilprac

Jha, M.N. and Kujur, Grace. 2009. Media support to Agriculture Extension. Delhi: Audience Research Unit, Directorate General, All India Radio.

Kuewumi, J.B. 2009. Radio: How it Impacts the Listener Personally. Babcock University Mass Communication J., 2(1): 138-149. 
Oguchi, O., Ajaegbu, Babafemi, J., Akintayo, Melody, M., Akinjiyan. 2015. Radio Listening Habits among University Students and Their Attitude towards Programmes (A Study of Redeemers University Students). Int. Knowledge Sharing Platform, Vol 5, Page 12 , http://www.iiste.org/Journals/index.php/RHS S/article/view/23453.

Onabajo, S. 1999. Essentials of Broadcast Writing and Production. Lagos: Gabi Concept Ltd.

How to cite this article:

Romica Bhat, Neemo Dhar. 2017. FM Radio and Listening Habits of Younger Generation: A Study of Four Major Markets of Delhi. Int.J.Curr.Res.Aca.Rev. 5(4), 6-11. doi: https://doi.org/10.20546/ijcrar.2017.504.002
Rajalakshmi C. 2012. Emerging Paradigm of FM Radio. Int. J. Information Technol. Computer Sci. Perspectives, Vol. 1(1): pp 49-52.

Santoki, A., Ashwin. 2015. Factor Analysis: A Study of Consumer Behavior towards FM Radio in Surat City. Int. J. Appl. Res., Vol. 1(12), pp 1011-1016.

Tacchi, Jo, A. 2009. Radio and Affective rhythm in the everyday. The Radio J. Int. 